\title{
Duration of stimulation in patients with polycystic ovarian syndrome undergoing ICSI: Does it affect the outcome?
}

Mohamed Taman, MD; Maher Elesawy, MD; Yasser Mesbah, MD Department of Obstetrics and Gynaecology, Mansoura University Hospital, Mansoura Faculty of Medicine, Mansoura, Egypt.

Corresponding author:

Mohamed Taman, MD

Lecturer

Department of Obstetrics and

Gynaecology

Mansoura University Hospital

Mansoura Faculty of Medicine

Mansoura, Egypt

Tel.: +200103516395

Email : Dr_mohammed_elsayed@

mans.edu.eg
Coauthers

Maher Elesawi, MD

Lecturer

Department of Obstetrics and Gynaecology

Mansoura University Hospital

Mansoura Faculty of Medicine

Mansoura, Egypt

Email: maherelesawi@yahoo.com

Yasser mesbah, MD

Associate professor

Department of Obstetrics and Gynaecology

Mansoura University Hospital

Mansoura Faculty of Medicine

Mansoura, Egypt

Email: yasermesbah@yahoo.com

Short running title:

Effect of ovarian stimulation on maturity of oocytes

Source of funding:

The study has no funding interest.

Conflict of interest Statement:

Declarations of interest none

IRB (Date \& No.):

2019/07/23.R.19.07.559.R1

Statement of prior presentation or publication and/or abstract/poster p Statement of prior presentation or publication and/or abstract/poster presentation:

The manuscript has not been published nor submitted for publication elsewhere except as a brief abstract in the proceedings of a scientific meeting or symposium. 


\section{Abstract}

Back ground: Oocyte and embryo quality are affected by the duration of ovarian stimulation in different categories of patients undergoing ICSI specially for those having polycystic ovarian syndrome as they undergo ovarian stimulation usinglow dose step up antagonist protocol.

Methods: Retrospective analysis of 139 patient underwent ovarian stimulatiaon using antagonist protocol and freeze all policy

Results: Patients were divided into 3 groups according to the duration of ovarian stimulation (group A $\leq 8$ days, group B 9-10 days, group $\mathrm{C} \geq 11$ days). We found that in spite of having no statistically significant difference in the total number of retrieved oocytes, there was statistically significant difference in the median number of germinal vesicle oocytes between group A and group C (3 (1-13) \& 1(0-5) P value $=0.01)$. Also this difference is present between group B and group C (3 (1-11) \& $1(0-5)$ P value $=$ $0.01)$. For metaphase II oocytes there was a statistically significant difference in the median number between group A and group B (3 (0-8) \& 5 (1-14) $\mathrm{P}$ value $=0.001)$. Also this difference is present between group A and group C (3 (0-8) \& $3(3-12) \mathrm{P}$ value $=0.001)$. There was no statistically significant difference in the total number of embryos in between the 3 groups.

Conclusion: We found that it seems to be safe to extend the duration of stimulation more than 8 days when treating patients with polycystic ovarian syndrome undergoing IVF/ICSI, as it was associated with more increase in mature oocytes (MII)

Key words: polycystic ovarian syndrome, antagonist protocol, freeze all, ovarian hyperstimualtion syndrome, intracytoplasmic sperm injection

\section{Introduction}

Polycystic ovary syndrome (PCOS) affects $8-13 \%$ of subfertile females in the reproductive-age (1). A gonadotrophin releasing hormone $(\mathrm{GnRH})$ antagonist protocol is recommendedfor women having PCOS and will undergo an in-vitro fertilization or intracytoplasmic sperm injection (IVF / ICSI) cycle. As it is known to reduce the duration of stimulation, total gonadotrophin dose and incidence of ovarian hyperstimulation syndrome (OHSS) (2). Human chorionic gonadotropin (HCG) administration for final oocyte maturation is the standard trigger of ovu- lation in controlled ovarian hyperstimulation $(\mathrm{COH})$. It is administered when at least1-2 leading follicles reach $\geq 18 \mathrm{~mm}$ or 3 folliclesreach $\geq 17 \mathrm{~mm}$ in diameter. However, GnRH agonist is recommended to be used for final oocyte maturation in cases predicted to be at high risk of developing OHSS as PCOS patients.

The number of dominant follicles areconsidered as important determinants for HCG administration. Obviously, it is not suitable for all patients with different ovarian reserve specially in PCOS with a high ovarian reserve (3).It is also known that the number of mature oocytes and good quality embryos are related to the proportion of mature follicle on the day of humanchorionic gonadotropin trigger(4).

Consequently, the quality of retrieved oocytes and the fertilized embryos are correlated with pregnancy outcomes (5). Complete maturation of the oocyte determines oocyte quality. Complete maturation of oocytes includes both nuclear maturation and cytoplasmic maturation. For oocyte nuclear maturation, resumption and progression of meiosis to MII cannot be used as the only determinant of an oocyte's developmental competence (6). Formation of good quality embryos and occurrence of pregnancyshould be also considered after excluding other factors which are involved in the process of implantation. Pregnancies were reported after 7-12 days of controlled stimulation of ovarian cycles (7). We aimed to determine whether the duration of ovarian hyperstimulation affects the quality of embryos on post-retrieval day 3 .

\section{Material and methods}

We conducted a hospital based retrospective study to evaluate the effect of duration of ovarian stimulation on embryo quality in patients diagnosed to have polycystic ovarian syndrome underwenttrial of ICSI cycles using the GnRH antagonist protocol with the use of GnRHagonist as a trigger of ovulation and freeze all policy as a preventive methods of OHSS . Participants in this study were group of sub fertile females attended to Mansoura university hospital fertility care unit and werediagnosed to have polycystic ovarian syndrome according to Rotterdam criteria (8). We investigated patients' hospital files in the past five years (January 2014 till January 2019).

\section{Inclusion criteria}

a) Patient age $>20$ years and $<40$ years

b) Patients diagnosed to have polycystic ovarian 
syndrome according to Rotterdam criteria(8)

c) Patients underwent IVF or ICSI due to one or more of the following indications:

a. Clomiphene citrate resistant patients

b. Unilateral or bilateral Fallopian tube obstruction, salpingectomy or tubal ligation

c. Semen analysis showed: oligoasthenozoospermia or investigation results showed obstructive azoospermia

\section{Exclusion criteria}

a) Patients known to have chromosomal anomalies

b) Male factor subfertility due to having non-obstructive azoospermia

c) Patient with body mass index $>30 \mathrm{~kg} / \mathrm{m}^{2}$

d) Patients underwent ovarian stimulation using the long agonist protocol

e) Patients underwent final maturation of oocytes using the HCG trigger

f) Patients poor ovarian reserve according to Bolognia criteria(9)

After revising patients' files all base line demographic data were collected. We selected patients underwent ovarian stimulation according to the following protocol; Pre cycle treatment with oral contraceptive pills (as a method of follicular synchronization) then a wash out period of 5 days then started HMG ovarian stimulation in the second day of menstruation according to BMI and the ovarian response (starting dose was 75-150 IU) for 5 days. GnRH antagonist protocol was used in a fixed manner was given in the 6th day of HMG stimulation(Cetrorelix 0.25 mg subcutaneous injection). HMG administration was continued in a step up manner. Triggering of ovulation was done when at least 3 dominant follicles of $\geq 17 \mathrm{~mm}$ diameter were reached. We selected only patients underwent final maturation of oocytes using GnRH agonist and freeze all policy as a preventive method of OHSS.Oocyte retrieval was performed 34-36 hours after triggering of ovulation. Oocyte quality was assessed by embryologist and classified into (atretic - germinal vesicle (GV) - MI -MII -post mature)(10).Intracytoplasmic sperm injection (ICSI) was done for all mature oocytes. Embryo quality was assessed morphologically at the 3rd day and it was classified into (grade A- grade B -grade C- discarded embryos) according to the degree of asymmetry and fragmentation(11). The data wereanalysed after classifying patients into 3 groups according to the duration of ovarian stimulation. Group A consisted of patientswho spent 8 days or less duringovarian stimulation, Group B consisted of pa- tients who spent 9 or10

days duringovarian stimulation and Group C patients who spent 11 days or more duringovarian stimulation.

\section{Outcome measurements}

Primary outcome

The primary outcome of this study is the number of grad A embryos in the 3 groups at the 3rd day after oocyte retrieval.

\section{Secondary outcome}

The secondary outcomes of this study will be the degree and severity of ovarian hyperstimulation syndrome(OHSS), the rate of mature and immature oocytes in relation to duration of stimulation and the number of grad B and grade C embryos in the 3 groups at the 3rd day after oocyte retrieval.

\section{Statistical analysis}

Statistical analysis and data interpretation:

Data were fed to the computer and analysed using IBM SPSS Corp. Released 2013. IBM SPSS Statistics for Windows, Version 22.0. Armonk, NY: IBM Corp. Qualitative data were described as number and percent. Testing of normality was done using Kolmogrov-Smirnov test. Quantitative data were described as median (minimum and maximum) for non-parametric data and mean, standard deviation for parametric data. Significance of the obtained results was judged at the (0.05) level.

\section{Data analysis}

Qualitative data:

- Chi-Square test was used for comparison of 2 or more groups

- Monte Carlo test was used as correction for ChiSquare test when more than $25 \%$ of cells have count less than 5 in tables $(>2 * 2)$.

Quantitative data between groups:

Parametric tests:

- Student t-test was used to compare 2 independent groups

- One Way ANOVA test was used to compare more than 2 independent groups with Post Hoc Tukey test to detect pair-wise comparison Non Parametric tests:

- Mann-Whitney U test was used to compare 2 independent groups

- KruskalWallis test was used to compare more than 2 independent groups with Mann Whitney $\mathrm{U}$ test to detect pair-wise comparison 


\section{Spearman's correlation:}

The Spearman's rank-order correlation was used to determine the strength and direction of a linear relationship between two non-normally distributed continuous variables and / or ordinal variables.

\section{$\underline{\text { Results }}$}

The mean ages of patients in the 3 groups were $(30,31 \& 28$ years $)$ respectively. Also the mean body mass indices were $(28.1,27.2 \& 27.9 \mathrm{~kg} / \mathrm{m} 2)$ respectively. There were no statistically significant differences between the 3 groups in the base line characteristics and demographic data (tablel). The starting doses of FSH which wereadjusted according to BMI showed no statistically significant differences between the three groups (146.6,135.5,136.3 IU respectively). However, there werestatistically significant differences in the sum of total doses of HMG used during ovarian stimulation (table 1). As regard the endometrial response to ovarian stimulation there were no statistically significant differences in the means of endometrial thickness at time of $\mathrm{GnRH}$ agonist trigger administration or the grade of endometrial pattern in the 3 groups (table 1). We found also that there were no statistically significant differencesin the total number of retrieved oocytes nor the serum estradiol level at time of trigger administration between the 3 groups. Also there were no statistically significant differences in the markers of ovarian hyperstimulation syndrome (OHSS) (serum $\mathrm{E} 2$ level $\geq 3500 \mathrm{pg} / \mathrm{dl}$ \& retrieval of $\geq 15$ oocytes) between the 3 groups (table 1). On the other hand, when we compered the quality of post retrieval oocytes, we found that there werestatistically significant differences in the median number of germinal vesicle oocytes between group A and group C (3 $(1-13) \& 1(0-5) \mathrm{P}$ value $=0.01)$. Also this difference is present between group B and group C (3 (1-11) $\& 1(0-5) \mathrm{P}$ value $=0.01)$. There was a statistically significant difference in the median number of metaphase I oocytes between group A and group B (5 $(2-11) \& 4(0-12) \mathrm{P}$ value $=0.01)$. Also this difference was present between group A and group C (5 $(2-11) \& 3(0-12) \mathrm{P}$ value $=0.01)$. For median number of metaphase II oocytes, there was a statistically significant difference between group A and group B $(3(0-8)$ \& 5 (1-14) $\mathrm{P}$ value $=0.001)$ (table 2). However, there was no statistically significant difference in the median number of atretic follicles between the 3 groups. For postmature oocytes, we found that there was a statistically significant difference in the median number between group A and group B also this difference is present between group A and group $\mathrm{C}$ (table 2). From the previously mentioned date we can conclude that the number of MI oocytes is likely to be higher when the duration of ovarian stimulation was 8 days or less. However, the number of MII oocytes was higher when duration of stimulation was between 9-11 days (table 2).

There were no statistically significant differences in the totalnumber of embryos between the 3 groups. After comparing the good quality embryos between the 3 groups we found that there was statistically significant difference in the number of grade A embryo between group A and group B (26/262 (9.9\%) $\& 168 / 683(24.6 \%) \mathrm{P}$ value $=0.04)$ and the same difference was present between group A and group C $(26 / 262(9.9 \%) \& 42 / 96(43.75 \%) \mathrm{P}$ value $=0.006)$. Also there were nostatistically significant differences in the number of grade B embryos between the 3 groups.However, there was a statistically significant difference between group A and group B if we compared the number of grade $C$ embryos (123/262 $(46.9 \%) \& 167 / 683(24.5 \%) \mathrm{P}$ value $=0.009)$. After comparing the sum of grade A and grade B embryos in the 3 groups, we found that there was a statistically significant difference between group A and group B only (133/262 (50.8\%) \& 496/683 $(72.6 \%)$ Pvalue $=0.013)($ table 3$)$. We found that there was a positive correlation between number of grade A embryo(figure 1) or number of grade A plus grade B (figure 2)embryos and the duration of ovarian stimulation when not exceeding 11 days. Also we found that there was a negative correlation between the number of immature oocytes, number of postmature oocytes and the duration of stimulation when it was less than 8 days (table 4). There was no relation between the marker of OHSS in this study (serum estradiol level and number of retrieved oocytes) and the duration of ovarian stimulation (table 5).

\section{Discussion}

Data from our study suggest that the quality of retrieved oocytes in patients diagnosed to have polycystic ovarian syndrome underwent ICSI using antagonist protocol wasrelated to the duration of ovarian stimulation i.e: when the duration was 8 days or less the chances of having immature (GV, atretic) oocytes were increased. On the other hand, the embryo quality at the 3rd day after oocyte retrieval has positive correlation with duration of stimulation i.e. the chance of having grade $\mathrm{C}$ embryos is going to increase when the duration of ovarian stimulation is less than 8 days. The relation between type of stimulation protocol, quality of embryos and proportion 
of dominant follicles(PDF) (the number of $\geq 18 / \geq 10$ $\mathrm{mm}$ follicles) at time of HCG or GnRH agonist trigger were studied(12) andit was found that there was no relation between clinical pregnancy rate and the degree of PDF however, it was found that postponing $\mathrm{HCG}$ or $\mathrm{GnRH}$ agonist trigger till the degree of PDF become between $20 \%-40 \%$ or more than $40 \%$ was associated with more risk of OHSS inspite of having more numbers of fertilized oocytes . In our study weinvestigated the effect of duration of ovarian stimulation after using $\mathrm{GnRH}$ antagonist protocol with administration of $\mathrm{GnRH}$ agonist as a trigger of ovulationand freeze all policy because it is considered to be the safest method of prevention of OHSS (13). The duration of stimulation while usingGnRH antagonist protocol also was studied in normal and poor responders(14)and it was found that less than 6 days of stimulation were not sufficient for oocyte maturation and extending the duration to 10-12 days of stimulation was considered to have positive correlation with MII oocytes in normal responders. But 6 days duration of ovarian stimulation may be enough duration for oocyte maturation for patients known to be poor responders(14) and this may be explained by the use of different stimulation protocols in such group of patients and staring stimulation with higher doses of $\mathrm{HMG}$ compared to patients having PCOS. The maturation rate of retrieved oocyte was found also to be higher with middle and high proportion when the follicles were divided according to their size $(\geq 17$ $\mathrm{mm} / \geq 10 \mathrm{~mm}$ follicles ratio on the day of human chorionic gonadotropinadministration) into (Low proportion: $30 \%$, Middle proportion: $30 \%-60 \%$, High proportion: $\quad 60 \%)(4)$, these resultswere found in patients received ovarian stimulation with antagonist protocol only. However, the were no statistically significant differences in implantation rates in the three groups. Also, it was found that a duration less than 9 days of ovarian stimulation was associated with more embryos and with more than $10 \%$ fragmentation on post-retrieval day 3(5).However, this was studied in a group of patients received the long agonist protocol. In our study we analysed cases treated with oral contraceptive pills before ovarian stimulation with antagonist protocol to avoid the effect of asynchronous growth of the cohort of follicles on the maturity of oocytes as it is one of the main disadvantages during the use of antagonist protocol(15). Also nowadays with the improvement of in vitro culture for oocytes there is an increasing use of in vitro maturation IVM of oocytes specially in patients with polycystic ovarian syndrome to eliminate the risk of OHSS in this category of patients(16).For the fertilized oocytes we evaluated the embryo quality and all good quality embryos were cryopreserved at day 3 post retrieval. However, nowadays there is an increasingorientation toward keeping the embryos in vitro till day 5 after retrieval. A systematic review and meta-analysis showed comparable results in the live birth rate between embryo transfer at day 3 and day 5 after oocytes retrieval (17). As blastocyst transfer is considered as a method of natural selection of good quality embryos.in our local protocol we used cryopreservation of embryos at the cleavage stage (day 3 ) and if we have more than 4 grade A embryos we allow in vitro culture after thawing till day 5 and we do embryo transfer only for the best one or 2 blastocyst according to the morphological scoring (18). It was also found that there was a positive association between the number of retrieved oocytes and the number of top quality embryos either at the cleavage stage or at the blastocyst stage (19).In our study we found that most of patients had elevated markers of OHSS(E2 level $\geq 3500 \mathrm{pg} /$ dl-retrieval of $\geq 15$ oocytes) showed mild clinical manifestations and achieved rapid clinical improvement with such protocol and there were no reported ICU or hospital admission of any of them. This protocol is considered to be applicable toward the trend of decreasing or eliminating the critical effects of OHSS(20).

In conclusion we found that it seems to be safe to extend the duration of stimulation more than 8 days when treating patients with PCOS underwent IVF/ICSI using antagonist protocol and $\mathrm{GnRH}$ agonist trigger and freeze all policy, as it was associated with more increase in mature oocytes(MII) and good quality embryos (grade A). Limitation of the study

It is a retrospective study and used the assessment of embryo quality at day 3 of oocyte retrieval than day 5 assessment of blastocyst. We recommend conducting a prospective study using blastocyst assessment of in comparison to day 3 assessment of blastomere.

\section{Acknowledgment}

We acknowledge that all authors have contributed significantly, and that all authors agree with the content of the manuscript.

\section{Disclosure}

All authors disclose no conflict of interest. 


\section{$\underline{\text { References }}$}

1. Bozdag G, Mumusoglu S, Zengin D, Karabulut E, Yildiz BOJHR. The prevalence and phenotypic features of polycystic ovary syndrome: a systematic review and meta-analysis. Human Reproduction, 2016;31:12 :2841-2855.

2. Teede HJ, Misso ML, Costello MF, Dokras A, Laven J, Moran L, et al. Recommendations from the international evidence-based guideline for the assessment and management of polycystic ovary syndrome. Human Reproduction, 2018;33:9:1602-1618.

3. Lin H-Y, Li Y, Wang W-J, Qiu Q, Zhang Q-X, Li YJCmj. Role of the proportion of dominant follicles in patients with polycystic ovary syndrome undergoing in vitro fertilization-embryo transfer. Chinese medical journal, 2019;132:12:144814453.

4. Hu X, Luo Y, Huang K, Li Y, Xu Y, Zhou C, et al. New perspectives on criteria for the determination of HCG trigger timing in $\mathrm{GnRH}$ antagonist cycles. Medicine,2016;95:20.

5. Yoldemir TJGE. Does the duration of gonadotropin stmulation affect embryo quality on post-retrieval day 3? . Gynecological Endocrinology, 2011;27:5:324-330.

6. Leibfried-Rutledge ML, Florman HM, First NLJTmbof. The molecular biology of mammalian oocyte maturation. The molecular biology of fertilization, 1989:259-301.

7. Borini A, Lagalla C, Sciajno R, Distratis V, Bonu Ma, Cattoli M, Et Al. Artificial Reproductive Technology Achievements For Optimizing Embryo Quality. Annals Of The New York Academy Of Sciences, 2004;1034:1:252-261.

8. ESHRE, The Rotterdam, et al. Revised 2003 consensus on diagnostic criteria and long-term health risks related to polycystic ovary syndrome. Fertility and sterility, 2004, 81:1: 19-25.

9. Ferraretti AP, Gianaroli LJHr. The Bologna criteria for the definition of poor ovarian responders: is there a need for revision? Human reproduction, 2014;29:9:1842-1845.

10. Lazzaroni-Tealdi E, Barad DH, Albertini DF, Yu Y, Kushnir VA, Russell H, et al. Oocyte scoring enhances embryo-scoring in predicting pregnancy chances with IVF where it counts most. PLoS One, 2015;10:12:e143632.

11. Depa-Martynow M, Jedrzejczak P, Pawelczyk LJFhec. Pronuclear scoring as a predictor of em- bryo quality in in vitro fertilization program. Folia histochemica et cytobiologica, 2007;45:1:85-89.

12. Lin H-Y, Li Y, Wang W-J, Qiu Q, Zhang Q-XJC$\mathrm{mj}$. Role of the proportion of dominant follicles in patients with PCOS undergoing in vitro fertilization-embryo transfer. Chinese medical journal, 2019; 132:12: 1448

13. Costello MF, Misso ML, Balen A, Boyle J, Devoto L, Garad RM, et al. Evidence summaries and recommendations from the international evidence-based guideline for the assessment and management of polycystic ovary syndrome: assessment and treatment of infertility. Human reproduction open. 2019;2019:1:hoy021.

14. Yang Y-C, Li Y-P, Pan S-P, Chao K-H, Chang $\mathrm{C}-\mathrm{H}$, Yang $\mathrm{J}-\mathrm{H}$, et al. The different impact of stimulation duration on oocyte maturation and pregnancy outcome in fresh cycles with GnRH antagonist protocol in poor responders and normal responders. Taiwanese Journal of Obstetrics and Gynecology,2019;58:4:471-476.

15. Al-Inany HG, Youssef MA, Aboulghar M, Broekmans F, Sterrenburg M, Smit J, et al. GnRH antagonists are safer than agonists: an update of a Cochrane review. Human reproduction update, 2011;17:4: 435-435

16. Allahveisi A, Yousefian E, Rezaie M, Nikkhoo Bjae. Comparison Of Morphometric And Morphology Oocytes After In Vitro Maturation Between Healthy Women And Patients With Polycystic Ovarian Syndrome. Acta Endocrinologica (Bucharest),2019;15:3:295.

17. Martins WP, Nastri CO, Rienzi L, van der Poel SZ, Gracia C, Racowsky C. Blastocyst vs cleavage-stage embryo transfer: systematic review and meta-analysis of reproductive outcomes. Ultrasound in Obstetrics \& Gynecology, 2017;49:5:583-591.

18. Nasiri N, Eftekhari-Yazdi P. An overview of the available methods for morphological scoring of pre-implantation embryos in in vitro fertilization. Cell Journal (Yakhteh), 2015;16:4:392-405.

19. Vermey BG, Chua SJ, Zafarmand $\mathrm{MH}$, Wang R, Longobardi S, Cottell E, et al. Is there an association between oocyte number and embryo quality? A systematic review and meta-analysis. Reproductive biomedicine online, 2019;39:5:751-763.

20. Banker M, Garcia-Velasco JA. Revisiting ovarian hyper stimulation syndrome: Towards OHSS free clinic. Journal of human reproductive sciences, 2015;8:1:13-7. 
Table (1) Demographic data and base line characteristic of the 3 groups

\begin{tabular}{|c|c|c|c|c|}
\hline & $\begin{array}{c}\text { Group A } \\
\leq 8 \text { days of } \\
\text { stimulation } \\
n=45\end{array}$ & $\begin{array}{c}\text { Group B } \\
\text { 9--10 days of } \\
\text { stimulation } \\
n=83\end{array}$ & $\begin{array}{c}\text { Group C } \\
\geq 11 \text { days of } \\
\text { stimulation } \\
n=11\end{array}$ & $\begin{array}{c}\text { Test of } \\
\text { significance }\end{array}$ \\
\hline $\begin{array}{l}\text { Age/years } \\
\text { Mean } \pm \text { SD }\end{array}$ & $30.18 \pm 4.8$ & $31.2 \pm 6.03$ & $28.9 \pm 5.6$ & $\begin{array}{l}\mathrm{F}=1.08 \\
\mathrm{P}=0.34\end{array}$ \\
\hline $\begin{array}{l}\mathrm{BMI}\left(\mathrm{Kg} / \mathrm{m}^{2}\right) \\
\text { Mean } \pm \mathrm{SD}\end{array}$ & $28.12 \pm 2.5$ & $27.2 \pm 2.9$ & $27.9 \pm 2.01$ & $\begin{array}{l}\mathrm{F}=1.68 \\
\mathrm{P}=0.191\end{array}$ \\
\hline $\begin{array}{l}\text { Type of infertility N (\%) } \\
\text { primary } \\
\text { secondary }\end{array}$ & $\begin{array}{l}33(73.3) \\
12(26.7)\end{array}$ & $\begin{array}{l}59(71.1) \\
24(18.9)\end{array}$ & $\begin{array}{c}10(90.9) \\
1(9.1)\end{array}$ & $\begin{array}{c}\mathrm{MC} \\
\mathrm{P}=0.376\end{array}$ \\
\hline $\begin{array}{l}\text { Duration of infertility /years } \\
\text { Median(Min-Max) }\end{array}$ & $7.0(2.0-18.0)$ & $6.0(1.0-20.0)$ & $6.0(4.0-9.0)$ & $\begin{array}{c}\mathrm{KW} \\
\mathrm{P}=0.749\end{array}$ \\
\hline $\begin{array}{l}\text { Cycle rhythm N (\%) } \\
\text { Oligomenorrhea } \\
\text { Regular }\end{array}$ & $\begin{array}{l}41(91.1) \\
4(8.9)\end{array}$ & $\begin{array}{l}75(90.4) \\
8(9.6)\end{array}$ & $\begin{array}{l}11(100.0) \\
0(0.0)\end{array}$ & $\begin{array}{c}\mathrm{MC} \\
\mathrm{P}=0.563\end{array}$ \\
\hline $\mathrm{AMH} / \mathrm{ng} / \mathrm{ml}$ & $3.8(1.0-10.6)$ & $3.1(1.2-13.0)$ & $4.09(2.5-16.0)$ & $\begin{array}{c}\mathrm{KW} \\
\mathrm{P}=0.076\end{array}$ \\
\hline Basal FSH / mIU/mL & $5.8(1.9-10.6)$ & $5.2(1.2-10.1)$ & $4.2(2.7-8.1)$ & $\begin{array}{c}\mathrm{KW} \\
\mathrm{P}=0.165\end{array}$ \\
\hline $\begin{array}{l}\text { Number of ICSI trials } \\
\text { Median (min-max) }\end{array}$ & $1.0(0.0-6.0)$ & $0.0(0.0-7.0)$ & $1.0(0.0-5.0)$ & $\begin{array}{c}\mathrm{KW} \\
\mathrm{P}=0.114\end{array}$ \\
\hline $\begin{array}{l}\text { Starting dose of HMG / IU/ day } \\
\text { mean } \pm \text { SD }\end{array}$ & $146.6 \pm 15.6$ & $135.5 \pm 29.7$ & $136.3 \pm 30.3$ & $\begin{array}{c}\mathrm{F}=2.72 \\
\mathrm{P}=0.069\end{array}$ \\
\hline $\begin{array}{l}\text { Endometrial thickness at time } \\
\text { of trigger } / \mathrm{mm} \text { mean } \pm \mathrm{SD}\end{array}$ & $11.80 \pm 1.97$ & $11.81 \pm 1.66$ & $12.91 \pm 3.11$ & $\begin{array}{l}F=1.69 \\
\mathrm{P}=0.187\end{array}$ \\
\hline $\begin{array}{l}\text { Endometrial shape at time of } \\
\text { trigger } \\
\mathrm{n}(\%)\end{array}$ & & & & \\
\hline Triple & $34(75.6)$ & $57(68.7)$ & $8(72.7)$ & $\mathrm{MC}$ \\
\hline Homogenous & $11(24.4)$ & $26(31.3)$ & $3(27.3)$ & $\mathrm{P}=0.709$ \\
\hline
\end{tabular}

BMI: body mass index, FSH:Follicle-Stimulating Hormone, AMH:anti-mullerian hormone, HMG:human menopausal gonadotropin, ICSI:intracytoplasmic sperm injection

MC: Monte Carlo test, F: One-way ANOVA test, KW: Kruskal Wallis test

*statistically significant (if $\mathrm{p}<0.05$ )

Similar superscripted letters denote significant difference between groups 
Table (2) Differences in number of retrieved oocytes, oocytes quality and serum estradiol level between 3 groups

\begin{tabular}{|c|c|c|c|c|}
\hline & $\begin{array}{c}\text { Group A } \\
\leq 8 \text { days of } \\
\text { stimulation } \\
n=45\end{array}$ & $\begin{array}{c}\text { Group B } \\
\text { 9-10 days of } \\
\text { stimulation } \\
n=83\end{array}$ & $\begin{array}{c}\text { Group C } \\
\geq 11 \text { days of } \\
\text { stimulation } \\
n=11\end{array}$ & $\begin{array}{c}\text { Test of } \\
\text { significance }\end{array}$ \\
\hline $\begin{array}{l}\text { Number of oocytes } \\
\text { median (min-max) }\end{array}$ & $16(7-30)$ & $15(8-32)$ & $12(8-25)$ & $\begin{array}{c}\mathrm{KW} \\
\mathrm{P}=0.266\end{array}$ \\
\hline $\begin{array}{l}\geq 15 \\
<15\end{array}$ & $\begin{array}{l}22(48.9) \\
23(51.1)\end{array}$ & $\begin{array}{l}50(60.2) \\
33(39.8)\end{array}$ & $\begin{array}{l}8(72.7) \\
3(27.3)\end{array}$ & $\begin{array}{c}\mathrm{MC} \\
\mathrm{P}=0.264\end{array}$ \\
\hline $\begin{array}{l}\text { Number of GV oocytes } \\
\text { median (min-max) }\end{array}$ & $3(1.0-13.0)^{\mathrm{a}}$ & $3(1.0-11.0)^{\mathrm{b}}$ & $1(0.0-5.0)^{\mathrm{ab}}$ & $\begin{array}{c}\mathrm{KW} \\
\mathrm{P}=0.01^{*}\end{array}$ \\
\hline $\begin{array}{l}\text { Number of M1 oocytes } \\
\text { median (min-max) }\end{array}$ & $5(2.0-11.0)^{\mathrm{ab}}$ & $4(0.0-12.0)^{\mathrm{a}}$ & $3(0.0-12.0)^{b}$ & $\begin{array}{c}\mathrm{KW} \\
\mathrm{P}=0.01^{*}\end{array}$ \\
\hline $\begin{array}{l}\text { Number of M2 oocytes } \\
\text { median (min-max) }\end{array}$ & $3(0.0-8.0)^{\mathrm{ab}}$ & $5(1.0-14.0)^{\mathrm{a}}$ & $5(3.0-12.0)^{\mathrm{b}}$ & $\begin{array}{c}\mathrm{KW} \\
\mathrm{P}=0.001^{*}\end{array}$ \\
\hline $\begin{array}{l}\text { Number of Atretic oocytes } \\
\text { median (min-max) }\end{array}$ & $1(0.0-8.0)$ & $0.0(0.0-4.0)$ & $1(0.0-5.0)$ & $\begin{array}{c}\mathrm{KW} \\
\mathrm{P}=0.096\end{array}$ \\
\hline $\begin{array}{l}\text { Number of Post mature } \\
\text { oocytes } \\
\text { median (min-max) }\end{array}$ & $3(1.0-8.0)^{\mathrm{ab}}$ & $0.0(0.0-5.0)^{\mathrm{a}}$ & $0.0(0.0-2.0)^{\mathrm{b}}$ & $\begin{array}{c}\mathrm{KW} \\
\mathrm{P}<0.001 *\end{array}$ \\
\hline $\begin{array}{l}\text { Serum E2 level / pg/mL } \\
\text { median (min-max) }\end{array}$ & $\begin{array}{c}3017 \\
(1041-8560)\end{array}$ & $\begin{array}{c}2434 \\
(1078-8166)\end{array}$ & $\begin{array}{c}1869 \\
(1224-7558)\end{array}$ & $\begin{array}{c}\mathrm{KW} \\
\mathrm{P}=0.068\end{array}$ \\
\hline $\begin{array}{l}<3500 \mathrm{pg} / \mathrm{mL} \\
\geq 3500 \mathrm{pg} / \mathrm{mL}\end{array}$ & $\begin{array}{l}28(62.2) \\
17(37.8)\end{array}$ & $\begin{array}{l}58(69.9) \\
25(30.1)\end{array}$ & $\begin{array}{l}8(72.7) \\
3(27.3)\end{array}$ & $\begin{array}{c}\mathrm{MC} \\
\mathrm{P}=0.630\end{array}$ \\
\hline
\end{tabular}

GV: Germinal vesicle, MI: metaphase I, MII: metaphase II, E2: estradiol

MC: Monte Carlo test, F: One-way ANOVA test, KW: Kruskal Wallis test

*statistically significant (if $\mathrm{p}<0.05$ )

Similar superscripted letters denote significant difference between groups

Table (3) difference in the quality of embryos between the 3 groups

\begin{tabular}{|c|c|c|c|c|}
\hline & $\begin{array}{c}\text { Group } A \\
\leq 8 \text { days of } \\
\text { stimulation } \\
n=45\end{array}$ & $\begin{array}{c}\text { Group B } \\
\text { 9--10 days of } \\
\text { stimulation } \\
n=83\end{array}$ & $\begin{array}{c}\text { Group C } \\
\geq 11 \text { days of } \\
\text { stimulation } \\
n=11\end{array}$ & $\begin{array}{c}\text { Test of } \\
\text { significance }\end{array}$ \\
\hline $\begin{array}{l}\text { Number of embryos } \\
\text { median (min-max) }\end{array}$ & $5(2.0-13.0)$ & $7(2.0-17.0)$ & $6(2.0-17.0)$ & $\begin{array}{c}\mathrm{KW} \\
\mathrm{P}=0.248\end{array}$ \\
\hline $\begin{array}{l}\text { Number of Grade A embryos } \\
\text { (Number/total number ) }\end{array}$ & $\begin{array}{l}26 / 262 \\
(9.9 \%)\end{array}$ & $\begin{array}{l}168 / 683 \\
(24.6 \%)\end{array}$ & $\begin{array}{c}42 / 96 \\
(43.75 \%)\end{array}$ & $\begin{array}{c}\mathrm{p} 1=0.04^{*} \\
\mathrm{p} 2=0.006^{*} \\
\mathrm{p} 3=0.17\end{array}$ \\
\hline $\begin{array}{l}\text { Number of Grade B embryos } \\
\text { (Number/total number ) }\end{array}$ & $\begin{array}{l}107 / 262 \\
(40.8 \%)\end{array}$ & $\begin{array}{l}328 / 683 \\
(48.0 \%)\end{array}$ & $\begin{array}{c}27 / 96 \\
(28.13 \%)\end{array}$ & $\begin{array}{l}\mathrm{p} 1=0.435 \\
\mathrm{p} 2=0.441 \\
\mathrm{p} 3=0.21\end{array}$ \\
\hline $\begin{array}{l}\text { Number of Grade C embryos } \\
\text { (Number/total number ) }\end{array}$ & $\begin{array}{l}123 / 262 \\
(46.9 \%)\end{array}$ & $\begin{array}{l}167 / 683 \\
(24.5 \%)\end{array}$ & $\begin{array}{c}27 / 96 \\
(28.13 \%)\end{array}$ & $\begin{array}{l}\mathrm{p} 1=0.009^{*} \\
\mathrm{p} 2=0.258 \\
\mathrm{p} 3=0.795\end{array}$ \\
\hline $\begin{array}{l}\text { Number of Grade } \\
\text { A + B embryos } \\
\text { (Number/total number) }\end{array}$ & $\begin{array}{l}133 / 262 \\
(50.8 \%)\end{array}$ & $\begin{array}{l}496 / 683 \\
(72.6 \%)\end{array}$ & $\begin{array}{c}69 / 96 \\
(71.88 \%)\end{array}$ & $\begin{array}{c}\mathrm{p} 1=0.013^{*} \\
\mathrm{p} 2=0.207 \\
\mathrm{p} 3=0.96\end{array}$ \\
\hline
\end{tabular}

MC: Monte Carlo test

KW: Kruskal Wallis test 
*statistically significant (if $\mathrm{p}<0.05$ )

P1 denotes difference between group A and group B

P2 denotes difference between group A and group C

P3 denotes difference between group B and group C

Similar superscripted letters denote significant difference between groups

Table (4) Correlation between oocytes quality and duration of ovarian stimulation

\begin{tabular}{|lcc|}
\hline \multicolumn{1}{|c}{ Quality of oocytes } & & Duration of ovarian stimulation \\
Mature oocytes (MII,MI) & $\mathrm{r}$ & .037 \\
Immature oocytes & $\mathrm{p}$ & .664 \\
& $\mathrm{r}$ & $-.287^{* *}$ \\
Post matureoocytes & $\mathrm{p}$ & .001 \\
& $\mathrm{r}$ & $-.751^{* *}$ \\
\hline
\end{tabular}

MI: metaphase I MII: metaphase II

r: Spearman correlation co-efficient $\quad *$ statistically significant (if $\mathrm{p}<0.05$ )

Table (5) Correlation between markers of ovarian hyper stimulation syndrome (Serum estradiol (E2) level andnumber of retrieved oocytes) and duration of ovarian stimulation

\section{Duration of ovarian stimulation}

Serum estradiol (E2) level

Number of retrieved oocytes

r: Spearman correlation co-efficient $\quad *$ statistically significant (if $\mathrm{p}<0.05$ )
$-.148$
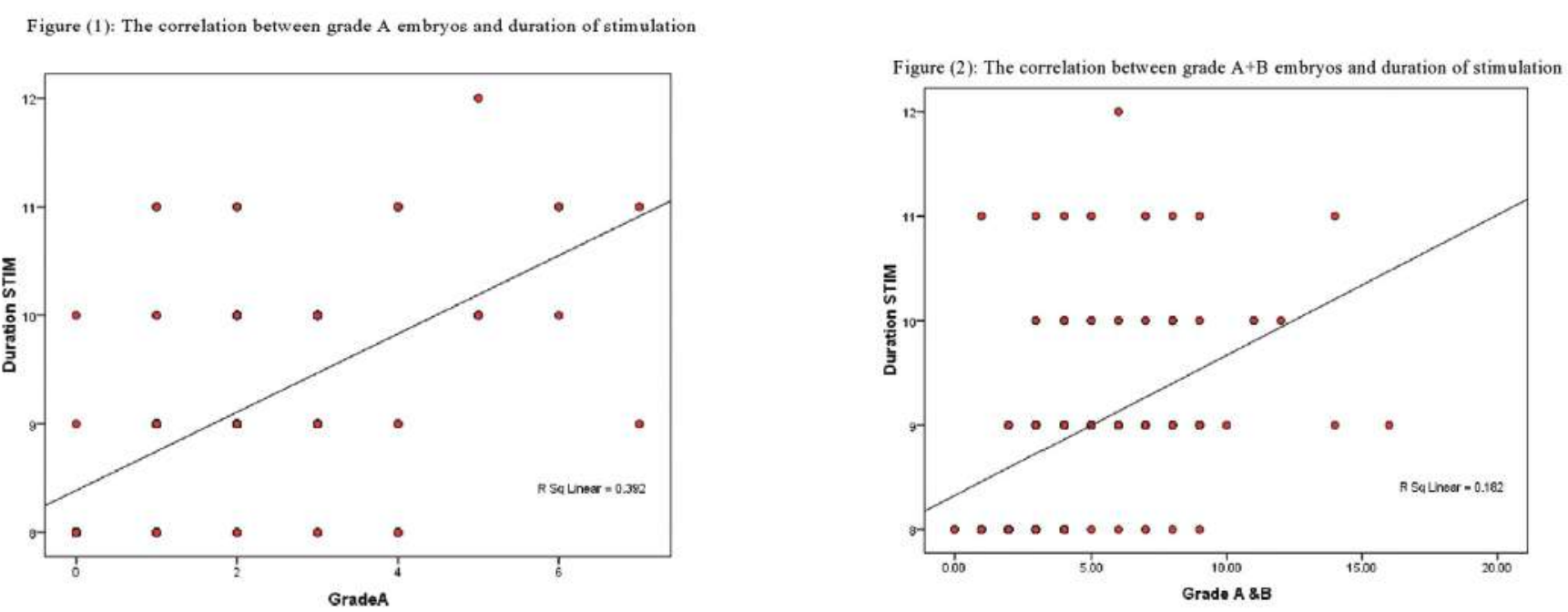

\section{Legends of figures}

Figure 1:There is a positive correlation between formation of grade A embryos at day 3 after oocyte retrieval and the duration of ovarian stimulation in patients having PCOS undergoing IVF/ICSI using GnRH antagonist protocol and $\mathrm{GnRH}$ agonist trigger for final oocyte maturation Figure 2:There is a positive correlation between formation of grade A + grade B embryos at day 3 after oocyte retrieval and the duration of ovarian stimulation in patients having PCOS undergoing IVF/ICSI using GnRH antagonist protocol and $\mathrm{GnRH}$ agonist trigger for final oocyte maturation 